\title{
FORGOTTEN ENCRUSTED URETERAL STENTS: ENDOUROLOGICAL MANAGEMENT
}

\author{
Vikas Gupta1, S. M. Datey², Rajat Lohia3, Himanshu Patidar ${ }^{4}$ \\ 12nd Year Post Graduate, Department of General Surgery, SAIMS, Indore. \\ 2 Professor and HOD, Department of General Surgery, SAIMS, Indore. \\ ${ }^{3} 2^{\text {nd }}$ Year Post Graduate, Department of General Surgery, SAIMS, Indore. \\ ${ }^{4} \mathrm{MCh}$, Department of Oncosurgery, SAIMS, Indore.
}

\section{ABSTRACT}

\section{PURPOSE}

To present single centre experience in various endourological approaches for treating forgotten encrusted ureteral stents associated with stone formation.

\section{MATERIALS AND METHODS}

From October 2013 to April 2015, 8 patients ( 6 males and 2 females) presented with forgotten encrusted and broken ureteral stents. The average indwelling time of the stent was 3.2 years (Range 1 to 7 years). The radiological investigation included X-rayKUB and intravenous urography to evaluate encrustation, stone burden, fragmentation and assess the renal function.

\section{RESULTS}

The stent was entirely encrusted in two patients, three patients had encrustation confined to the kidney and three patients had encrustation of the lower coil with one patient having encrustation of the ureter. Percutaneous nephrolithotomy was performed in 5 cases, retrograde ureteroscopy with intracorporeal lithotripsy in 3 patients, cystolithotripsy in 3 , while in one patient simple cystoscopic removal of the stent with minimal encrustation was carried out. All the 8 patients were stone and stent free in one session.

\section{CONCLUSION}

Endourological management of the forgotten encrusted stents is highly successful and avoids the need for open surgical techniques.

\section{KEYWORDS}

Stents, Forgotten, Endourological.

HOW TO CITE THIS ARTICLE: Gupta V, Datey SM, Lohia R, et al. Forgotten encrusted ureteral stents: Endourological management. J. Evolution Med. Dent. Sci. 2016;5(13):607-610, DOI: 10.14260/jemds/2016/138

\section{INTRODUCTION}

Ureteral stent placement is a common procedure in urology, which was first described by Zimskind et al. in 1967.[1] Indications - ureteral surgery/ureteral obstruction due to intrinsic or extrinsic causes, stones, strictures, UPJO, RPF, malignancies and congenital anomalies.[2][3][4][5][6] Early complications are pain, irritative symptoms and fever, while late and serious complications include encrustations, migration, fragmentations and stone formation when stents left for a long period of time. Patient was managed successfully by following procedures like PCNL, URS and TUCLT/PCCLT.

\section{MATERIALS AND METHODS}

This is a prospective type of study. The Duration of Study is from Oct 2013 to April 2015. The place where study is to be conducted is Sri Aurobindo Medical College and Post-graduate Institute, Indore, MP.

Financial or Other, Competing Interest: None.

Submission 28-12-2015, Peer Review 21-01-2016,

Acceptance 30-01-2016, Published 15-02-2016.

Corresponding Author:

Dr. Vikas Gupta,

Siddhanth, PG Hostel

Room No. 21, SAIMS Campus, Indore.

E-mail: vikasgupta114@yahoo.co.in

DOI: $10.14260 /$ jemds $/ 2016 / 138$
Sri Aurobindo Medical College and Post-graduate Institute in Indore (MP) being a Tertiary Care Centre is delivering state of art care to patients of Central India. Our Hospital of the Institute is well equipped and have all speciality and super-speciality courses. There are total of eight patients (Six Males and two Females) who presented with forgotten ureteral stents with severe encrustation. The mean duration of age is 37.3 years (Ranging from 21-60 years). All patients were operated elsewhere. The main reason for retention is either poor compliance or inability to counsel.

All were evaluated for stent encrustation with stone burden with following radiological procedures like X-ray, IVU and DTPA. In all patients routine blood investigations and urine cultures obtained. Treatment decision was observed on the basis of clinical and radiological findings. In stents with minimal encrustations on plain film radiography, a single gentle attempt was made with the grasping forceps. Combined endourological procedures like PCNL, CLT, URSL performed in one session. Postop plain film radiography is done to confirm stone free and stent free status.

\section{RESULTS}

Minimal indwelling time is 1 year, while maximum 7 years in a 60/F (History of open pyelolithotomy). Five patients were done in General Anaesthesia, two in regional Anaesthesia, while one patient was done under local Anaesthesia. 


\section{$\mathbf{G A}=\mathbf{5}$}

$\mathbf{R A}=\mathbf{2}$

$\mathrm{LA}=\mathbf{1}$

\begin{tabular}{|c|c|c|c|c|c|c|c|c|c|}
\hline \multirow[b]{2}{*}{$\mathbf{N}$} & \multirow[b]{2}{*}{ Age/Sex } & \multirow{2}{*}{$\begin{array}{c}\text { Initial Indications } \\
\text { for } \\
\text { Stenting }\end{array}$} & \multirow{2}{*}{$\begin{array}{l}\text { Indwelling } \\
\text { Time } \\
\text { (Years) }\end{array}$} & \multicolumn{3}{|c|}{ Site of Encrustation } & \multirow[b]{2}{*}{ Procedure } & \multirow{2}{*}{$\begin{array}{c}\text { Stent } \\
\text { Retrieved }\end{array}$} & \multirow{2}{*}{$\begin{array}{c}\text { Length of } \\
\text { Hospital } \\
\text { Stay } \\
\text { (Days) }\end{array}$} \\
\hline & & & & Kidney & Ureter & Bladder & & & \\
\hline 1 & $21 / \mathrm{M}$ & Left URSL & 1 & - & - & ++ & DJSR & Complete & 2 \\
\hline 2 & $24 / \mathrm{M}$ & Right Pyelolithotomy & 2 & +++ & - & - & Right PCNL & Fragmented & 4 \\
\hline 3 & $38 / \mathrm{F}$ & Left Pyelolithotomy & 5 & - & - & ++++ & CLT & Fragmented & 3 \\
\hline 4 & $26 / \mathrm{M}$ & Right Pyelolithotomy & 4 & ++++ & +++ & +++ & $\begin{array}{c}\text { Right } \\
\text { PCNL+ } \\
\text { CLT+URS } \\
\end{array}$ & Fragmented & 5 \\
\hline 5 & $28 / \mathrm{M}$ & Right Pyelolithotomy & 4 & ++++ & +++ & ++ & URS+PCNL & Fragmented & 4 \\
\hline 6 & $58 / \mathrm{M}$ & Right URSL & 2 & - & ++ & ++++ & URS+CLT & Fragmented & 3 \\
\hline 7 & $44 / \mathrm{M}$ & Left Nephrolithotomy & 1 & ++++ & - & - & Left PCNL & Complete & 3 \\
\hline 8 & $60 / F$ & Right Pyelolithotomy & 7 & ++++ & - & - & Right PCNL & Fragmented & 4 \\
\hline
\end{tabular}

In two patients sites of encrustation is in kidney, ureter and bladder and PCNL with URS was done, while in two patients stent was encrusted in bladder and DJSR and CLT was done. In three patients, stent was encrusted only in kidney and was removed surgically by PCNL. In only one patient, stent was encrusted in ureter and bladder and stent was removed surgically by URS and CLT.

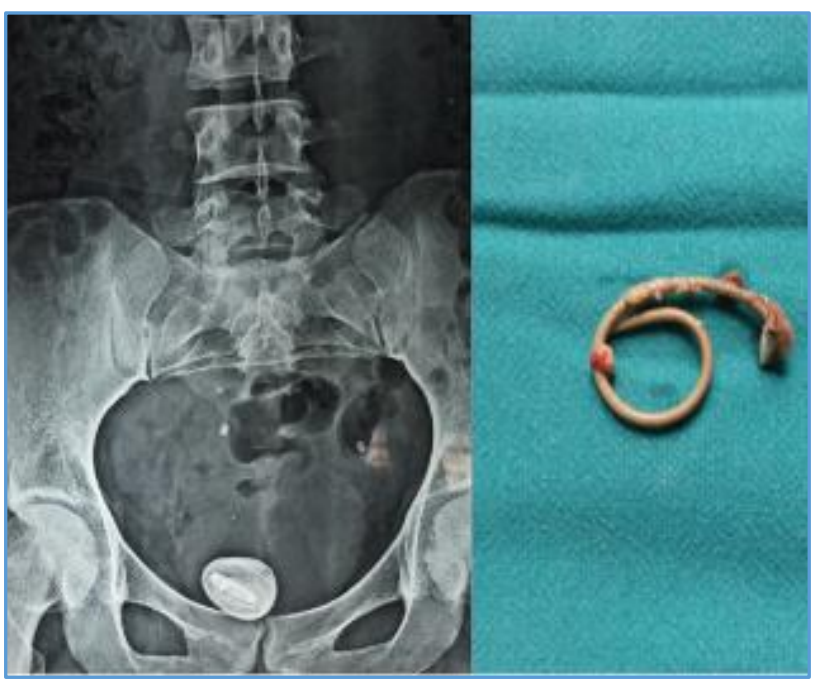

There is a 38 years female patient with history of pyelolithotomy, dysuria since 6 months. X-ray revealed displaced coiled stent into bladder. CLT procedure performed. Here is post-operative picture of coiled stent removed.

\section{Comparison with other studies}

- Degree of encrustation depends on dwelling time. ElFaqih et al. found encrustation increased from $9.2 \%$ at less than 6 weeks' time to $47.5 \%$ at 6 to 12 weeks to $76.3 \%$ at more than 12 weeks of dwelling time.[7] ElFaqih, et al. Polyurethane internal ureteral stents in treatment of stone patients: morbidity related to indwelling times. J Urol 1991;146:1487-91. Multiple endourological approaches or even open surgery are needed because of encrustations.

- $\quad$ Singh et al. described multiple accesses and approaches including open surgery to treat the retained stents.[8]
Singh I et al. Severely encrusted polyurethane ureteral stents: management and analysis of potential risk factors. Urology 2001;58:526-31.

- One stage removal of 12 encrusted retained ureteral stents - reported by Bukkapatnam et al. in 10 patients. Of these, 11 managed by ureteroscopy alone and in 1 patient treated through a percutaneous approach. They concluded stents can be removed in one sitting with minimal morbidity and short hospital stay.[9] Bukkapatnam et al. One-step removal of encrusted retained ureteral stents. J Urol 2003;170:1111-4. The result is comparable to our study, where all the patients were successfully managed in one stage with combined endourological approach with shorter hospital stay.

\section{DISCUSSION}

Double-J stents have been widely used for more than 2 decades for different indications. These forgotten stents can produce considerable morbidity and mortality due to extensive encrustation with significant stone burden, knot formation, upward migration and fragmentation.[10][11] Encrustation for forgotten stents associated with large stone burden is a serious problem due to complications like recurrent urinary tract infection, haematuria, obstruction and renal failure.[12] Common risk factors for stent encrustation are long indwelling time, urinary sepsis, history of stone disease, chemotherapy, pregnancy, chronic renal failure and metabolic or congenital abnormalities.

Other factors implicated in the increased incidence of encrustations are chronic recurrent stone formations, metabolic predisposition to stone disease, congenital renal anomalies, malignant urinary obstruction and pregnancy. The risk of encrustation and fragmentation is dependent on the type of material of the stent. Silicon was found to be least prone to encrustation followed by polyurethane, silitek, percuflex and hydrogel coated polyurethane.

Fragmentations of polyurethane stents are four times as frequent as the silicone stents. Very few studies have introduced algorithms for the management of retained indwelling ureteral stents and practitioners are still debating on which method is the best for managing these encrusted stents. In order to avoid encrustation, it has been reported that 
a time period of between 2-4 months is considered optimal for Double-J stent removal or replacement.[13,12] Stents with a full coil are less prone to migrate than those with a J shape, stent materials with great memory, such as polyurethane are less prone to migrate than those with less memory such as silicone. Simple dislodgement or migration of silicone stents up into the kidney above a ureteral hindrance can be managed with extraction under fluoroscopic control and local anaesthesia. The distal dislocation can be managed by transurethral extraction of the stent.

The clinical presentation of a fragmented ureteral stent may vary with septic, irritative and haemorrhagic symptoms. Our approach towards management of these difficult stents is based on the findings of plain film radiography. Intravenous urogram and DTPA renogram is obtained to determine function of the kidney. Nephrostomy of second stent is done, if the patient presents with pyelonephritis and sepsis. Extracorporeal Shock Wave Lithotripsy (ESWL) is the initial treatment with stents with minimal encrustation. Silicone stents may be more advantageous than polyurethane stents due to lower risk of calcification and prolonged tensile strength for up to 20 months. Although, endourological management of these stents achieves success in majority of the cases with minimal complications, the best treatment that remains in prevention of this complication.

The treating surgeon should be very selective in placing these stents and they must be tracked very closely by documenting insertion and removal of these stents. All patients should be counselled with respect to the complications of long term use and advice when their stent should be removed. As mentioned earlier the degree of encrustation is dependent on the indwelling time, so it is necessary to keep the indwelling time as short as possible. Various authors have reported that indwelling time should be between 2-4 months is safe.[15,16,17,18,19] For patients requiring stent beyond this period, they should be kept on prophylactic antibiotics.

\section{Reasons for Forgotten Stents}

- Illiteracy among low socioeconomic class population.

- Improper follow-up due to non-compliance of the patient.

- Inadequate communication is the etiology of stent retention as was seen in these patients. Registry of the stent is to be maintained by all urologists. Complete ureteral stent tracker provides Complete Stent Tracking System for Urologists.

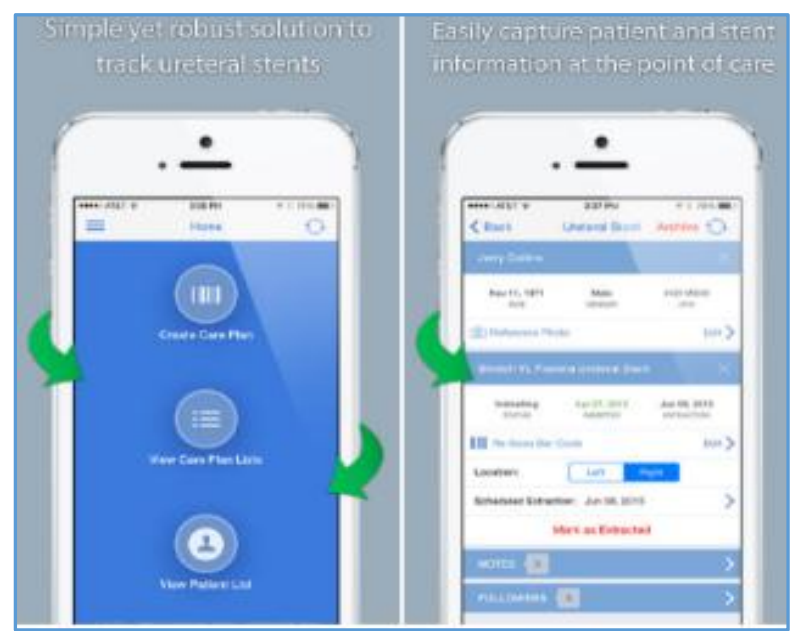

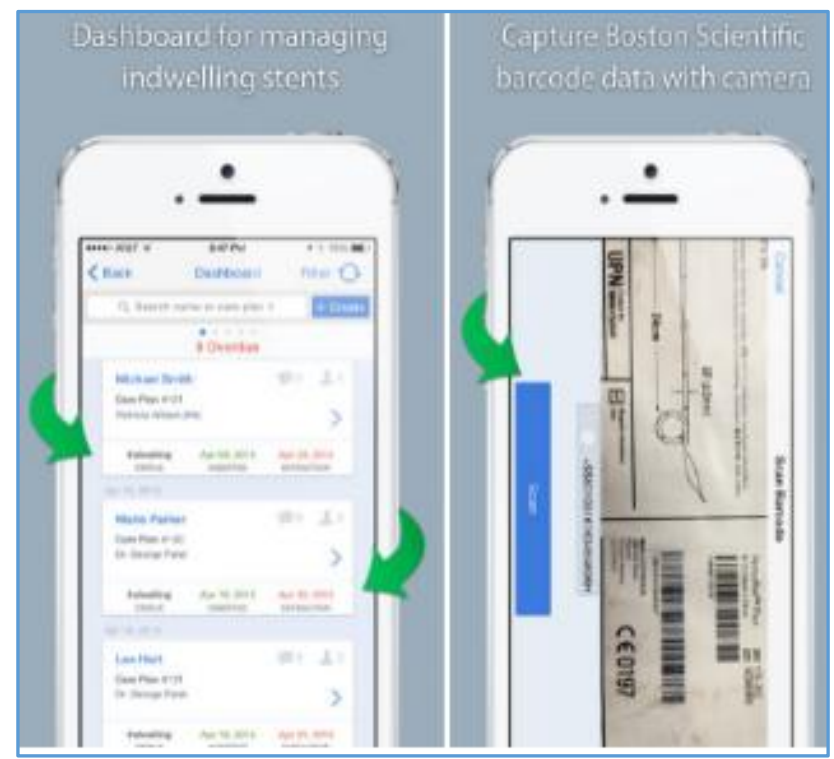

In first phase, we have to make a simple yet robust solution to track ureteral stents. In second phase is to easily capture patient and stent information at point of care. In phase three Dashboard has to be maintained for managing indwelling stents. In phase four is to Capture Boston Scientific Barcode Data with camera.

\section{REFERENCES}

1. El-Faqih, et al. Polyurethane internal ureteral stents in treatment of stone patients: morbidity related to indwelling times. J Urol 1991;146:1487-91.

2. Singh I, et al. Severely encrusted polyurethane ureteral stents: management and analysis of potential risk factors. Urology 2001;58:526-31.

3. Bukkapatnam, et al. One-step removal of encrusted retained ureteral stents. J Urol 2003;170:1111-4.

4. Zimskind PD, Fetter TR, Wilkerson HL. Clinical use of long-term indwelling silicone rubber ureteral splints inserted cystoscopically. J Urol 1967;97:80-4.

5. Saltzman B. Ureteral stents. Indications, variations and complications. Urol Clin North Am 1988;15:481-91.

6. Chew BH, Knudsen BE, Denstedt JD. The use of stents in contemporary urology. Curr Opin Urol 2004;14:111-5.

7. Hepperlen TW, Mardis HK, Kammandel H. The pigtail ureteral stent in the cancer patient.

J Urol 1979;121:17-8.

8. Gogas J, Markopoulos C, Kouskos E, et al. Metastatic retroperitoneal and mediastinal fibrosis as first sign of recurrence of breast cancer. Eur J Surg 2001;167:715-8.

9. Park DS, Park JH, Lee YT. Percutaneous nephrostomy versus indwelling ureteral stents in patients with bilateral non-genitourinary malignant extrinsic obstruction. J Endourol 2002;16:153-4.

10. Damiano R, Oliva A, Esposito C, et al. Early and late complications of double pigtail ureteral stent. Urol Int 2002;69:136-40.

11. Schulze KA, Wettlaufer JN, Oldani G. Encrustation and stone formation: complication of indwelling ureteral stents. Urology 1985;25:616-9.

12. Mohan-Pillai K, Keeley FX Jr, Moussa SA, et al. Endourological management of severely encrusted ureteral stents. J Endourol 1999;13:377-9. 
13. Flam TA, Brochard M, Zerbib M, et al. Extracorporeal shock-wave lithotripsy to remove calcified ureteral stents. Urology 1990;36:164-5.

14. Somers WJ. Management of forgotten or retained indwelling ureteral stents. Urology 1996;47:431-5.

15. Borboroglu PG, Kane CJ. Current management of severely encrusted ureteral stents with a large associated stone burden. J Urol 2000;164:648-50.

16. Lam JS, Gupta M. Tips and tricks for the management of retained ureteral stents. J Endourol 2002;16:733-41.
17. Eisner B, Kim H, Sacco D. Repeat knot formation in a patient with an indwelling ureteral stent. Int Braz J Urol 2006;32:308-9.

18. Monga $M$, Klein E, Castañeda-Zúñiga $W R$, et al. The forgotten indwelling ureteral stent: a urological dilemma. J Urol 1995;153:1817-9.

19. Singh V, Srinivastava A, Kapoor R, et al. Can the complicated forgotten indwelling ureteric stents be lethal? Int Urol Nephrol 2005;37:541-6. 